\title{
Molecular Identification of Bacterial Strains Producing Succinic Acid from Indian Sources
}

\author{
Hema N.* and K.P. Sreenath \\ Department of Botany, Bangalore University, Bangalore - 560 056, Karnataka, India.
}

\begin{abstract}
The present study includes molecular characterization of six bacterial strains isolated for succinic acid production from Indian region. $\mathrm{RFC}(\mathrm{P3}), \mathrm{BS}(\mathrm{D}), \mathrm{BS}(\mathrm{MC}), \mathrm{CRF}(\mathrm{S}), \mathrm{RFC}(\mathrm{W})$ and $\mathrm{RFC}(\mathrm{C})$ are the strains which were identified by $16 \mathrm{~S}$ rDNA sequencing and phylogenetic analysis. All the strains have been proved to be newly isolated strains of the species through genbank accession number from NCBI. RFC(P3) - Enterobacter cloacae HMI57, BS(D) - Bacillus amyloliquefaciens HMI57, BS(MC) - Enterobacter cloacae HEMI057, CRF(S) - Enterobacter cloacae HIND7557, RFC(W) - Bacillus subtilis HMRB715 and RFC(C) - Bacillus subtilis MHIRFC75 are the identified six organisms to be first reported for succinic acid production from Indian sources.

Keywords: Succinic acid production, $16 \mathrm{~S}$ rDNA analysis, Phylogenetic tree, Enterobacter cloacae, Bacillus sp.
\end{abstract}

*Correspondence: hemamuniraj@gmail.com; +91-9060667788

(Received: 23 September 2018; accepted: 07 November 2018)

Citation: Hema N. and K.P. Sreenath, Molecular Identification of Bacterial Strains Producing Succinic Acid from Indian Sources, $J$ Pure Appl Microbiol., 2018; 12(4):2313-2319. http://dx.doi.org/10.22207/JPAM.12.4.73

(c) The Author(s) 2018. Open Access. This article is distributed under the terms of the Creative Commons Attribution 4.0 International License which permits unrestricted use, sharing, distribution, and reproduction in any medium, provided you give appropriate credit to the original author(s) and the source, provide a link to the Creative Commons license, and indicate if changes were made. 


\section{INTRODUCTION}

Bio-based products are gaining wide acceptability and demand due to its sustainable benefits. Succinic acid has been proved to be one such bio-based chemical that can be produced through fermentation using renewable feedstock. Due to increased prices of limited petroleum feedstock for chemical production and its harmful effects, biological production of succinic acid wherein green house gas carbon dioxide is utilized, has attracted researches worldwide from past two decades.

According to report on "2018-2023 BioSuccinic Acid Market Global Key Player, Demand, Growth, Opportunities and Analysis Forecast" by Wise Guy Reports.com the Bio Succinic Acid Market is expected to grow at CAGR of $23.2 \%$ from 2018 to 2023.

Succinic acid, one of the most important platform chemicals is used as a precursor for many industrial important chemicals such as adipic acid, 1,4-butanediol, tetrahydrofuran, $\mathrm{N}$-methyl pyrrolidinone, 2-pyrrolidinone, succinate salts and gamma - butyrolactone ${ }^{1}$. 1, 4, BDO is the largest segment of the succinic acid market. High demand from 1,4, BDO is driving the industrial material segment. The succinic acid application market is segmented in seven major categories which are 1,4, BDO, Plasticizer, PBS, Solvent \& lubricant, Polyols, Pharmaceutical application and food \& beverages applications (Fig.1 $)^{2}$. Due to this wide applicability, Bio-succinic Acid Wins "Biofuels Digest, Chemical Of The Year Award" in 2017.

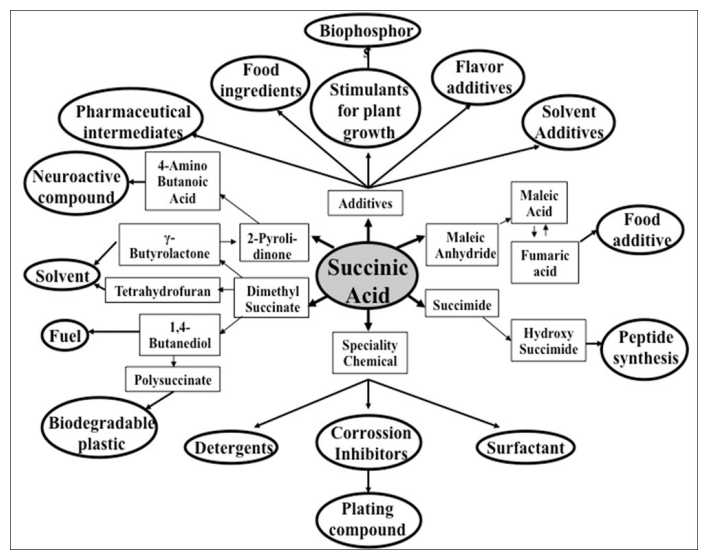

Fig. 1. Applications of Succinic acid (Source : Laufuhr-test.info,Images: Succinic acid)
Increasing interest, demand and environmental benefits associated with fermentative succinic acid production called up for the challenge of producing succinic acid economically. Several organisms such as Actinobacillus succinogenes, Mannheimia succiniciproducens, Anaerobiospirillum succiniciproducens, E.coli, Clostridium thermosuccinogenes, Corynebacterium glutamicum, Enterococcus faecalis, Bracteroids fragilis, Enterococcus flavescens, Klebsiella pneumoniae, Saccharomyces cerevisiae, Yarawo lipolitica, Aspergillus niger, Penicillium simplicissium etc were reported for the production of succinic acid ${ }^{3}$. Among them Actinobacillus succinogenes, Mannheimia succiniciproducens, Anaerobiospirillum succiniciproducens, Escherichia coli and Corynebacterium glutamicum are some of the widely studied strains ${ }^{4}$.

Strain capability, feedstock cost and fermentation technology are the key aspects for biological succinic acid production. This led to massive developments in the last few decades with respect to strain improvement, advancements in fermentative technologies, efforts to utilize various waste substrates efficiently to meet the needs for commercial scale production in an economically feasible way. Among which, strain development plays a prominent role in enhancing the efficiency and reducing the costs of the overall costs of the bioprocess. This has been accomplished by metabolic engineering of the organisms for maximizing succinic acid yield and minimizing the by-products.

Metabolic engineering of succinate producing strains such as Actinobacillus succinogenes ${ }^{5,6}$, Manheimia succiniproducens ${ }^{7}$, Anaerobiospirillum succiniproducens ${ }^{8}$, recombinant Escherichia coli ${ }^{9,10}$, Corynebacterium glutamicum $^{11,12,13}$, Saccharomyces cerevisiae (14,15,16 $^{2}$ were carried out leading to commercialization of the fermentation processes using the mutant strains ${ }^{17,18}$. Thus all the succinate producers used in industries are isolated and genetically modified for improved production ${ }^{19}$. Isolation of new strains opens up more opportunities for technology development for succinic acid production. Owing to this fact as objective, a study focusing on screening for isolation of new strains for succinic 
acid production was carried out. The present work reports the results of characterization of the isolated six strains which has wide opportunities to be explored for its industrial applications.

\section{MATERIALS AND METHODS \\ Source of the strains}

The strains used for the study were obtained by screening more than 90 isolates from various sources for succinic acid production ${ }^{20}$. Fourteen strains producing succinic acid were obtained. Six high yielding bacterial strains $\operatorname{RFC}(\mathrm{P} 3), \mathrm{BS}(\mathrm{D}), \mathrm{BS}(\mathrm{MC}), \mathrm{CRF}(\mathrm{S}), \mathrm{RFC}(\mathrm{W})$, and $\mathrm{RFC}(\mathrm{C})$ of the fourteen have been used as isolates from Indian sources for identification studies.

Molecular characterization and phylogenetic analysis

The DNA was isolated from the culture isolates. Its quality was evaluated on $1.0 \%$ Agarose Gel, a single band of high-molecular weight DNA has been observed. Fragment of $16 \mathrm{~S}$ rDNA gene was amplified by $27 \mathrm{~F}$ and $1492 \mathrm{R}$ primers. A single discrete PCR amplicon band of 1500 bp was observed when resolved on Agarose gel. The PCR amplicon was purified to remove contaminants. Forward and reverse DNA sequencing reaction of PCR amplicon was carried out with forward primer and reverse primers using BDT v3.1 Cycle sequencing kit on $A B I 3730 x \mid$ Genetic Analyzer. Consensus sequence of $16 \mathrm{~S}$ rDNA gene was generated from forward and reverse sequence data using aligner software.

The 16S rDNA gene sequences were compared with existing sequences in the NCBI database using the BlastN program.. Based on maximum identity score sequences were selected and aligned using multiple alignment software program Clustal W. Phylogenetic tree for strain RFC(P3) with different species of Enterobacteriaceae was constructed by Neighbourjoining method from 100 bootstrapping replicates using MEGA 5 software. Distance matrix of the other strains were generated and the phylogenetic tree was constructed by Neighbor-joining method from 1000 bootstrapping replicates using MEGA 7 software.

\section{RESULTS}

The molecular characterization of all the six strains carried out through 16S rDNA sequencing and phylogenetic analysis lead to the nucleotide sequences and construction of the phylogenetic tree of strains as given below :

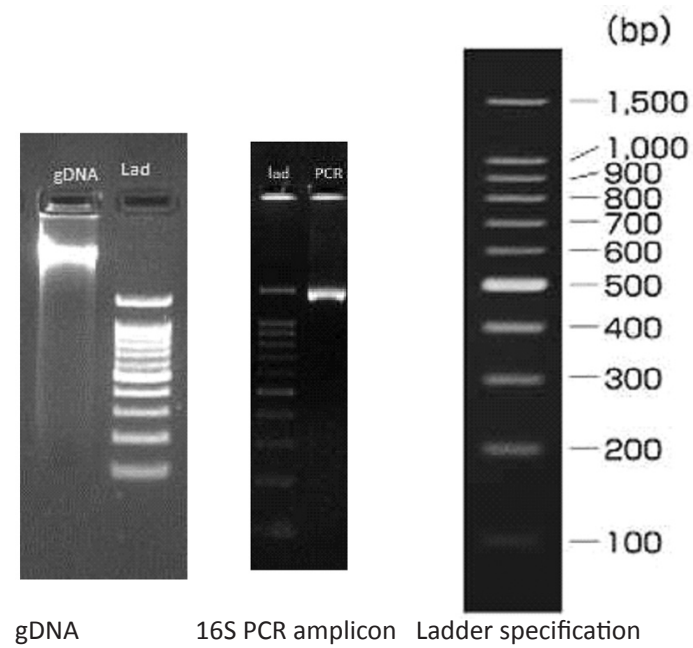

Fig. 2. gDNA and $16 S$ Amplicon $Q C$ data

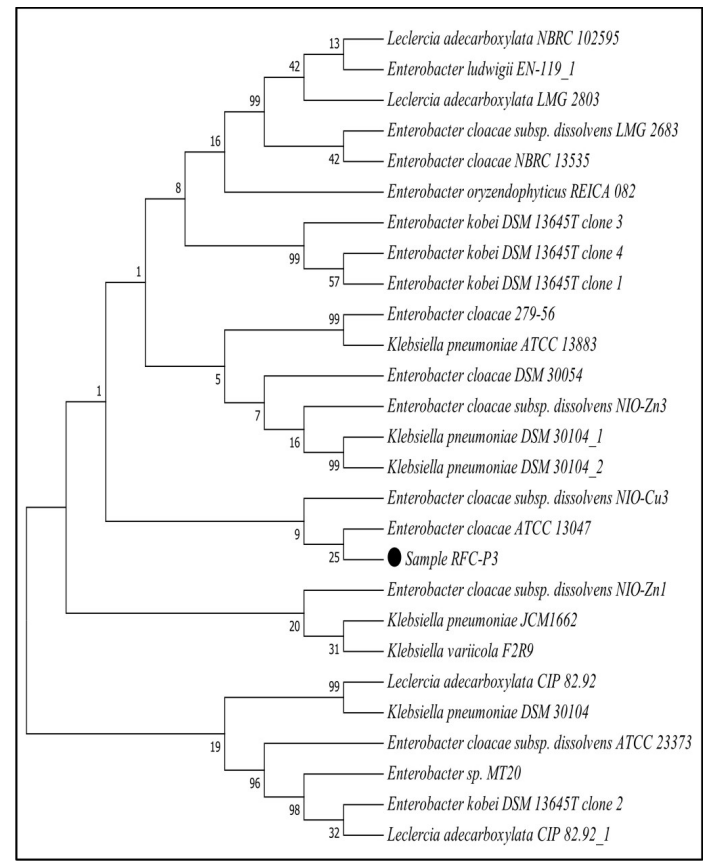

Fig. 3. Phylogenetic tree of RFC(P3) 


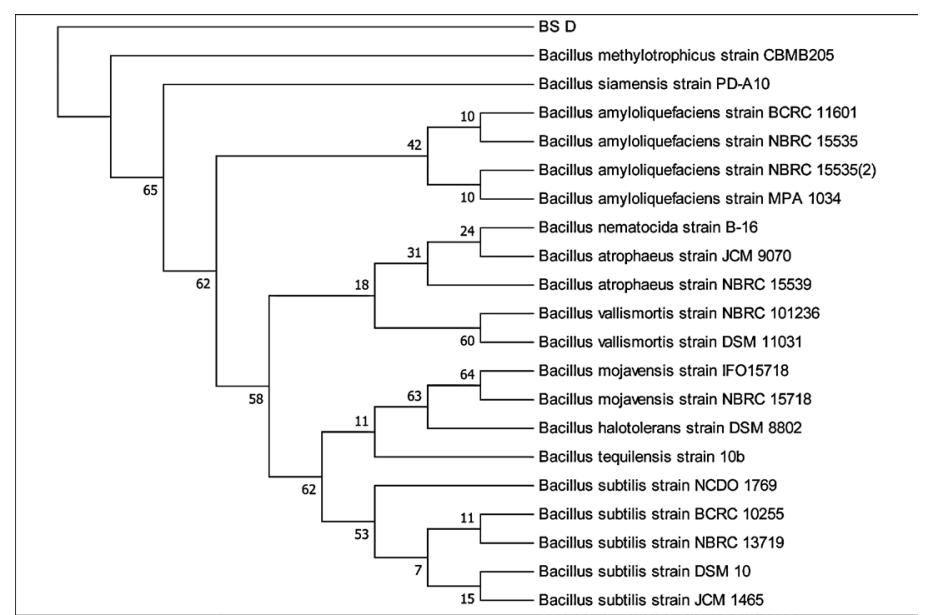

Fig. 4. Phylogenetic tree of BS(D)

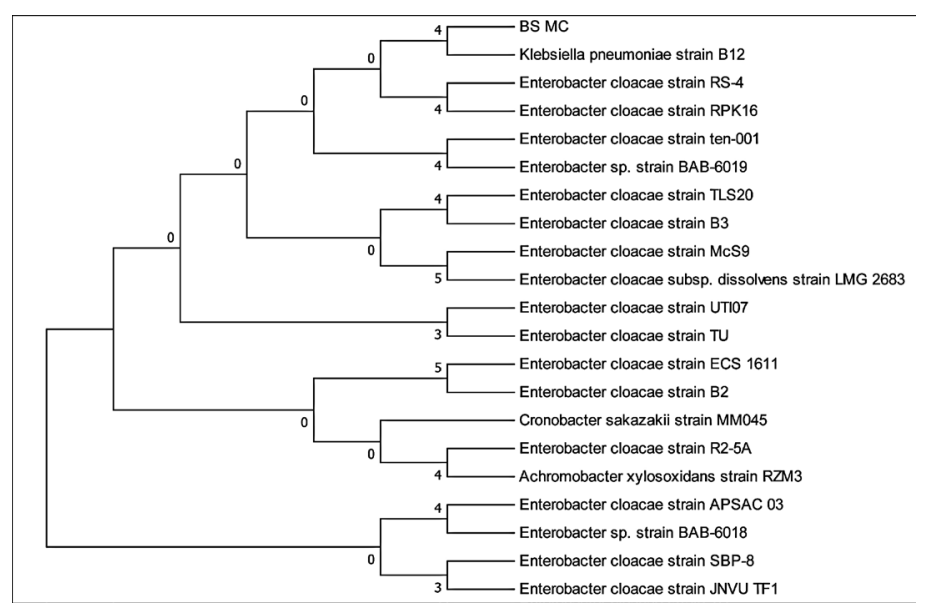

Fig. 5. Phylogenetic tree of $\mathrm{BS}(\mathrm{MC})$

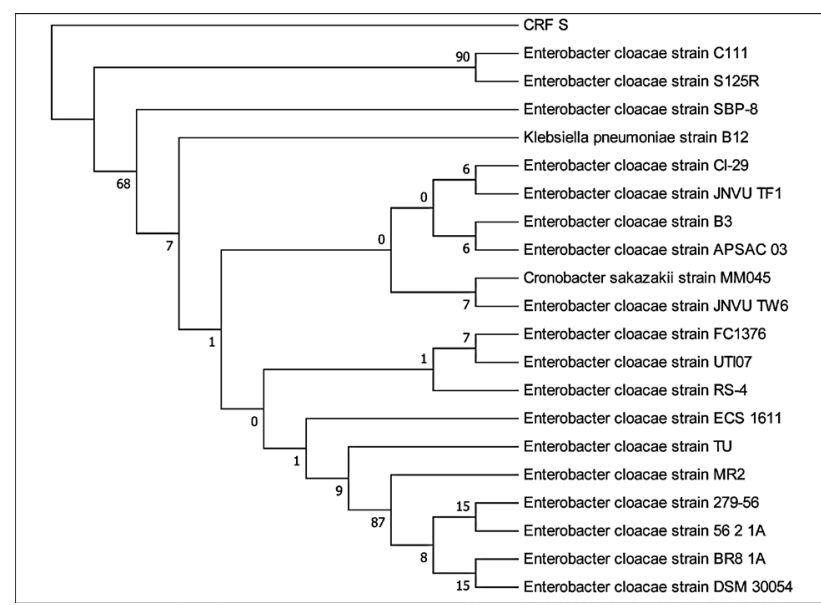

Fig. 6. Phylogenetic tree of CRF(S) 


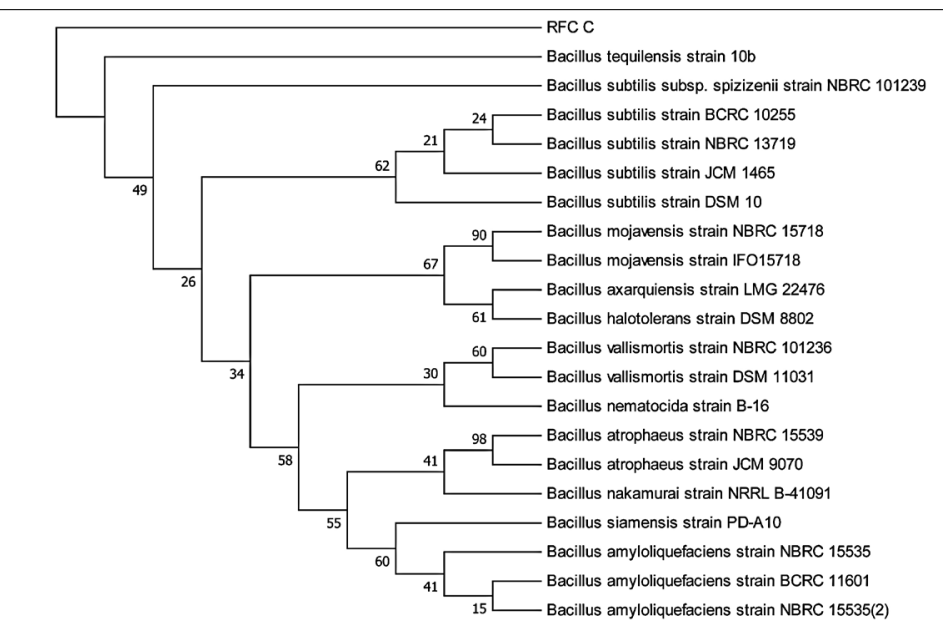

Fig. 7. Phylogenetic tree of RFC(C)

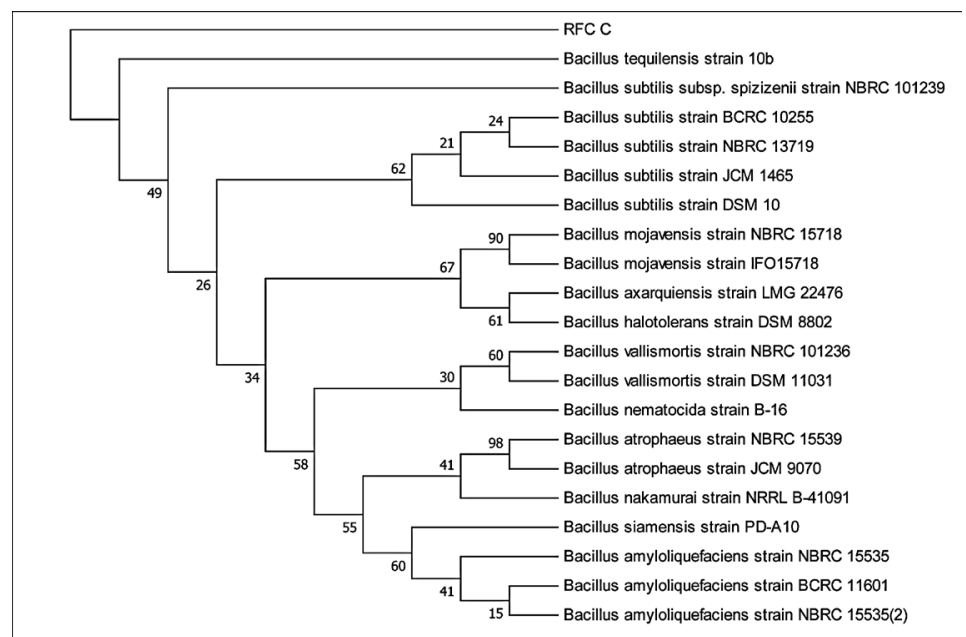

Fig. 8. Phylogenetic tree of RFC(W)

Distance matrix for sequences producing significance alignment were obtained for RFC(P3), $\mathrm{BS}(\mathrm{D}), \mathrm{BS}(\mathrm{MC}), \mathrm{CRF}(\mathrm{S}), \mathrm{RFC}(\mathrm{C})$ and $\mathrm{RFC}(\mathrm{W})$. Based on the greatest homology which is indicated by high score and low expect value the best match for the strains were found. The DNA sequence of $\mathrm{RFC}(\mathrm{P} 3)$ matches best with that of Enterobacter cloacae ATCC 13047. Sequence of BS(D) showed best with Bacillus amyloliquefaciens strain NBRC 15535 with 98\% similarity. Enterobacter cloacae strain TLS2O was the best match when compared with DNA sequence of BS(MC). Similarly CRF (S) showed best match with Enterobacter cloacae strain SBP-8 showing $99 \%$ similarity. The DNA sequences of the strains $R F C(C)$ and $R F C(W)$ matches best with Bacillus subtilis strain NBRC 13719 and with Bacillus subtilis strain DSM 10 respectively showing $99 \%$ similarity.

None of them showed $100 \%$ similarity to any of the strains in distance matrix generated. Thus the nucleotide sequences of the newly isolated strains were submitted to NCBI Genbank submission portal and accession numbers were obtained for all the six strains i.e RFC(P3), BS(D), $B S(M C), C R F(S), R F C(C)$ and $R F C(W)$. The details of the six strains isolated, source of isolation, identification, accession number obtained from NCBI Genbank and date of publish of the same in NCBI database has been summarized in Table 1. 
Table 1. Accession numbers of the newly isolated six strains for succinic acid production

\begin{tabular}{lllll}
\hline $\begin{array}{l}\text { Isolates and } \\
\text { Source }\end{array}$ & $\begin{array}{l}\text { Identification of } \\
\text { Isolates through 16S rDNA } \\
\text { sequencing and } \\
\text { phylogenetic analysis }\end{array}$ & $\begin{array}{l}\text { Code given to } \\
\text { Isolates for } \\
\text { Submission }\end{array}$ & $\begin{array}{l}\text { GenBank } \\
\text { Accession } \\
\text { Number }\end{array}$ & $\begin{array}{l}\text { Date of publish } \\
\text { in NCBI database }\end{array}$ \\
\hline $\begin{array}{l}\text { RFC(P3) } \\
\text { Rumen fluid } \\
\text { of cow }\end{array}$ & Enterobacter cloacae & $\begin{array}{l}\text { Enterobacter cloacae } \\
\text { HMI57 }\end{array}$ & MH570202 & 11-JUL-2018 \\
$\begin{array}{l}\text { BS(D) } \\
\text { Biogas slurry }\end{array}$ & Bacillus amyloliquefaciens & Bacillus amyloliquefaciens & MH819555 & 07-SEP-2018 \\
$\begin{array}{l}\text { BS(MC) } \\
\text { Rumen fluid } \\
\text { of cow }\end{array}$ & Enterobacter cloacae & $\begin{array}{l}\text { Enterobacter cloacae } \\
\text { HEMI057 }\end{array}$ & MK209628 & 28-NOV-2018 \\
$\begin{array}{l}\text { CRF(S) } \\
\text { Rumen fluid } \\
\text { of cow }\end{array}$ & Enterobacter cloacae & Enterobacter cloacae & MK212385 & 30-NOV-2018 \\
$\begin{array}{l}\text { RFC(C) } \\
\text { Rumen fluid } \\
\text { of cow }\end{array}$ & Bacillus subtilis & HD7557 & & \\
$\begin{array}{l}\text { RFC(W) } \\
\text { Rumen fluid } \\
\text { of cow }\end{array}$ & Bacillus subtilis & Bacillus subtilis & & \\
\hline HMRB715 & MK123381 & 10-NOV-2018 \\
\hline
\end{tabular}

\section{DISCUSSION}

Of the six succinic acid producing strains, three isolates $\mathrm{RFC}(\mathrm{P3}), \mathrm{BS}(\mathrm{MC})$ \& $\mathrm{CRF}(\mathrm{S})$ are three different strains belonging to Enterobacter cloacae; $\mathrm{RFC}(\mathrm{C}), \mathrm{RFC}(\mathrm{W})$ \& $\mathrm{BS}(\mathrm{D})$ are three different strains of Bacillus species. Among six strains, five are isolated from rumen fluid of cow wherein Enterobacter cloacae being dominant species. Enterococcus flavescens (21) and Klebsiella pneumoniae (22) are the only strains till date, reported for succinic acid production from Indian sources. None of the strains RFC(P3) - Enterobacter cloacae HMI57, BS(D) - Bacillus amyloliquefaciens HMI57, BS(MC) - Enterobacter cloacae HEMI057, CRF(S) - Enterobacter cloacae HIND7557, RFC(W) Bacillus subtilis HMRB715, RFC(C) - Bacillus subtilis MHIRFC75 identified have not been reported prior for succinic acid production from Indian sources.

\section{ACKNOWLEDGMENTS}

The authors gratefully acknowledge Principal, St. Joseph's College (Autonomous), Bangalore, for providing laboratory facilities for the above work. Our heartfelt thanks to
Dr. Purushothama, Professor, Department of Botany, St Joseph's College for his guidance and support. We are also thankful to Dr. Thamizhseran, Professor, Department of Botany, for his help during the research investigation.

\section{REFERENCES}

1. Pu Zheng, Jin-Jun Dong, Zhi-Hao Sun, Ye Ni, Lin Fang. Fermentative production of succinic acid from straw hydrolysate by Actinobacillus succinogenes. Bioresource Technology, 2009; $100: 2425-2429$.

2. Nhuan P. Nghiem, Susanne Kleff, Stefan Schwegmann. Succinic Acid: Technology Development and Commercialization. Fermentation, 2017; 3 : 26.

3. Joeri J. Beauprez, Marjan De Mey, Wim K. Soetaert. Microbial succinic acid production: Natural versus metabolic engineered producers. Process Biochemistry, 2010; 45 : 1103-1114.

4. Mariateresa Ferone, Francesca Raganati, Giuseppe Olivieri, Piero Salatin, Antonio Marzocchella. Succinic Acid Production from Hexoses and Pentoses by Fermentation of Actinobacillus succinogenes. Chemical 
Engineering Transactions, 2016; 49 : 211-216.

5. Guettler MV, Jain MK, Rumler D. Method for making succinic acid, bacterial variants for use in the process, and methods for obtaining variants. US Patent US5573931A; 1996.

6. Guettler MV, Jain MK, Soni BK. Process for making succinic acid, microorganisms for use in the process and methods for obtaining the microorganisms. US Patent US5723322A; 1996.

7. Sang Jun Lee, Hyohak Song, Sang Yup Lee. Genome-Based Metabolic Engineering of Mannheimia succiniciproducens for Succinic Acid Production. Appl Environ Microbiol, 2006; 72 : 1939-1948.

8. Guettler, M. V, M. Jain. Method for making succinic acid, Anaerobiospirillum succiniciproducens variants for use in process and methods for obtaining variants. US patent US 5521075 A; 1996.

9. Jantama, K., X. Zhang, J. C. Moore, K. T. Shanmugam, S. A. Svoronos, L. O. Ingram. Eliminating side products and increasing succinate yields in engineered strains of Escherichia coli. C. Biotechnol. Bioeng, 2008; 101 : 881-893.

10. Hyohak Song, Sang Yup Lee. Production of succinic acid by bacterial fermentation. Enzyme and Microbial Technology, 2006; 39 : 352-361.

11. Litsanov, B. M. Brocker, M. Bott. Toward homosuccinate fermentation : Metabolic engineering of Corynebacterium glutamicum for anaerobic production of succinate from glucose and formate. Appl. Environ. Microbiol, 2012; 78 : 3325-3337.

12. Okino S, R. Noburyu, M. Suda, T. Jojima, M. Inui, H.Yukawa. An efficient succinic acid production process in a metabolically engineered Corynebacterium glutamicum strain. Appl. Microbiol. Biotechnol, 2008; 81 : 459-464.

13. Hongtao Xu, Zhihui Zhou,Chen Wang, Zhongjun Chen, Heng Cai. Enhanced succinic acid production in Corynebacterium glutamicum with increasing the available NADH supply and glucose consumption rate by decreasing $\mathrm{H+-}$ ATPase activity. Biotechnol Lett, 2016; 38(7) : 1181-1186.
14. Andreas M. Raab, Gabi Gebhardt, Natalia Bolotina, Dirk Weuster-Botz, Christine Lang. Metabolic engineering of Saccharomyces cerevisiae for the biotechnological production of succinic acid. Metabolic Engineering, 2010; 12 : 518-525.

15. Ke-Ke Cheng, Gen-Yu Wang, Jing Zeng, JianAn Zhang. Improved Succinate Production by Metabolic Engineering. BioMed Research International, 2013; 5 : 1-12.

16. Ke-Ke Cheng, Xue-Bing Zhao, Jing Zeng Jian-An Zhang. Biotechnological production of succinic acid: current state and perspectives. Biofuels, Bioprod. Bioref, 2012; 6 : 302-318.

17. Mickel LA Jansen, Walter M van Gulik. Towards large scale fermentative production of succinic acid, Current Opinion in Biotechnology, 2014; 30 : 190-197.

18. Sudeep Vaswani. 2010. Bio-Based Succinic Acid, PEP Review 2010-14, Process Economics Program Menlo Park, California.

19. Jeon, Jong-Min, Rajesh Thangamani, Eunjung Song, Hyuk-Won Lee, Hong-Weon Lee, Yung-Hun Yang. Media Optimization of Corynebacterium glutamicum for Succinate Production Under Oxygen-Deprived Condition. J. Microbiol. Biotechnol, 2013; 23(2), 211-217.

20. Hema N, K P Sreenath. Screening for isolation of succinic acid producing microbes. Biosciences, Biotechnology Research Asia, 2018; 15 (2) : 327-333.

21. Lata Agarwal, Jasmine Isar, Gautam K Meghwanshi, Rajendra Kumar Saxena. Influence of environmental and nutritional factors on succinic acid production and enzymes of reverse tricarboxylic acid cycle from Enterococcus flavescens. Enzyme and Microbial Technology, 2006; 40 : 629-636.

22. Chandresh Thakker, Zainab Burhanpurwala, Gurdeep Rastogi, Yogesh Shouche, Dilip Ranade. Isolation and characterization of a new osmotolerant, non-virulent Klebsiella pneumoniae strain SAP for biosynthesis of succinic acid. Indian J Exp Biol, 2006; 44 : 142150. 